\title{
USING THE RESULTS OF MEASUREMENT IN READING IN TRAINING STUDENT-TEACHERS
}

\author{
M. ELIZABETH JAMES \\ State Normal School, Salem, Massachusetts
}

When the mechanics of reading are mastered, comprehension and speed in silent reading become the essential factors to be developed. In order to determine the achievement and the types of remedial work necessary, the teacher may make use of standard tests. The following account is a description of work of this kind carried on by student-teachers in the State Normal School, Salem, Massachusetts, under the direction of the supervising teacher of the third grade. As may be gathered from the account, the work covered a period of several months.

On January 25, 1922, the director of the school gave as a test Picture Supplement Scale 3 of the Burgess Scale for Measuring Ability in Silent Reading. This was the first test of the kind ever given to this class. The results were tabulated and the children grouped according to the suggestions given by Mrs. Burgess in the Elementary School Journal. ${ }^{\mathbf{x}}$ The results were poor; the average number of paragraphs read was 2.53, the standard being 4.90. It was clear that all but a very few needed much drill in both speed and comprehension. Of a class of fifty-two, there were ten who read none of the paragraphs correctly, while twelve others were able to read only one. Only twelve of the fifty-two exceeded the standard score. The distribution of scores is shown in Figure $\mathrm{I}$.

A chart was made with the name and score of each child written in the proper column so that the children themselves could see very plainly just what each individual accomplished. They were intensely interested in finding their names and scores.

In discussing the matter with the student-teachers, it was agreed that, while the results were affected somewhat by the fact that it was an entirely new experience to the children and that in many

× May Ayres Burgess, "Classroom Grouping for Silent-Reading Drill," Elementary School Journal, XXII (December, I92I), 269-78. 


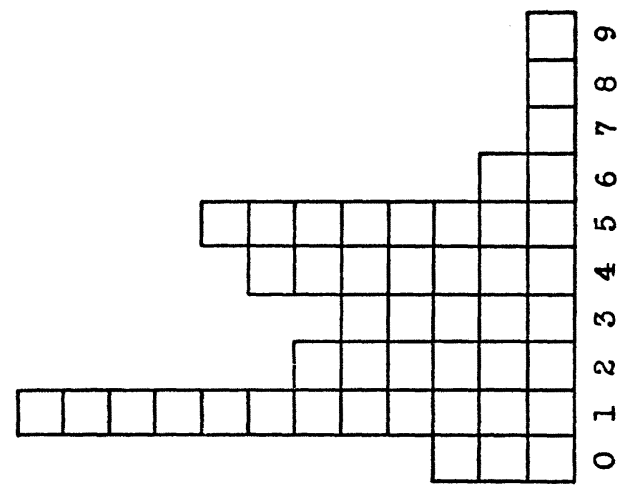

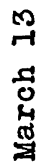

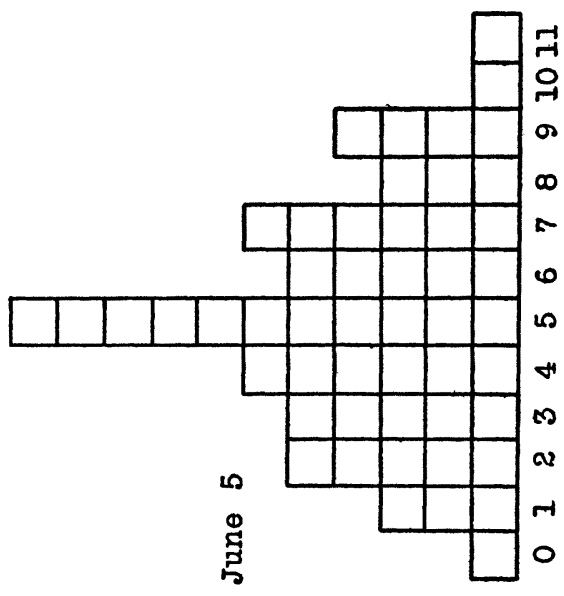

$\rightarrow$

.

赲
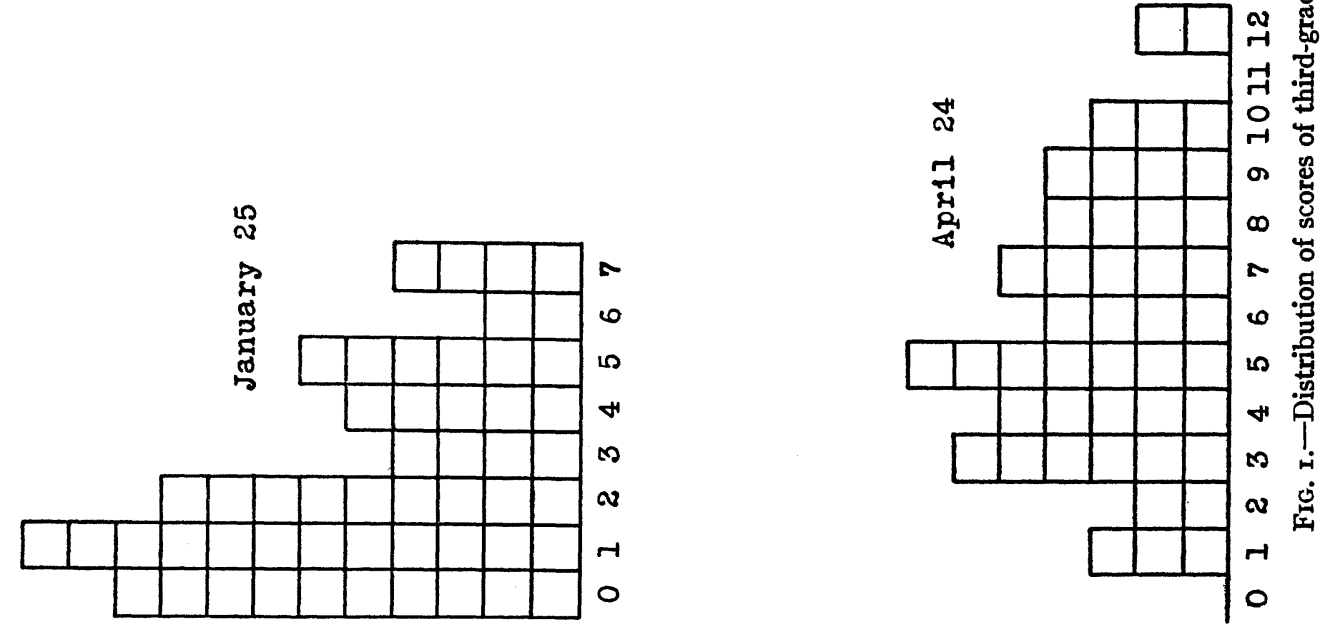

This content downloaded from 128.248.155.225 on September 19, 2016 06:56:36 AM All use subject to University of Chicago Press Terms and Conditions (http://www.journals.uchicago.edu/t-and- 
cases they did not understand that the simplest drawing results were most acceptable, they did point out weaknesses in certain aspects. Then the question arose as to what specific drill might be valuable to help the children increase their speed in reading and power of comprehension.

It was decided to make exercises similar to those in the Burgess scale and use them for drill in comprehension. The following exercises were made and tried first by the supervising teacher. They were made short and simple at first and then gradually longer.

I. This is a snowman. Draw his picture. Blacken the hat.

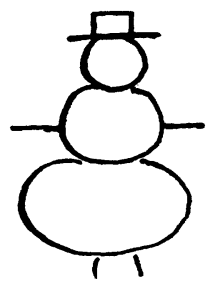

2. Draw this window. Write the letter $u$ in the two upper panes. Write the letter $l$ in the two lower panes.

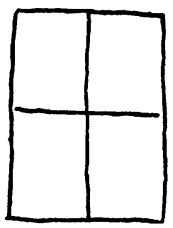

These exercises were written on the blackboard, accompanied by very simple drawings, while the children kept their eyes closed. Then at a given signal the pupils opened their eyes and began to read. They had previously been provided with paper and pencil. After each exercise had been carried out by the children, it was read and the result given so that they could check their errors.

The following exercises are examples of those submitted and tried by student-teachers.

I. Here are three squares. Draw them. Put the number I under the largest, the number 2 under the next largest, and the number 3 under the smallest.
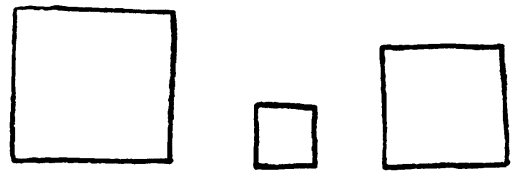
2. Here are three buttons. One has two holes in it; another has three holes in it; and the other has four holes in it. Draw these buttons on your paper. Draw a cross through the button with three holes. Draw a line through the button which has two holes but do not change the other.

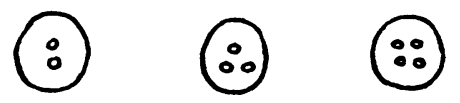

Some of the exercises originated by the student-teachers were rejected as not valuable for the purpose because they failed to make reading the most important feature. For instance, in the first of the two following illustrations the result depends mostly upon ability to count, and in the second too much drawing is required.

I. The numbers of the houses on one side of a street are I, 3, 5, 7, 9, II, I3, I5. Those on the other side begin with 2 and go to 18 . Write the missing numbers on the other side.

2. This is Johnny Sticks. He has a new suit. Draw him. Draw the new suit on him. His hat is missing. Draw it on his head.

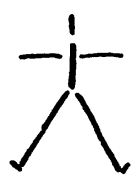

After some discussion of the difficulties in such exercises as these, the students were more discriminating and skilful in preparing subsequent exercises.

A discussion as to the type of exercises given so far brought out the fact that all were similar in one respect, namely, they all called for the following of simple directions, using drawing as the medium of expression and all related to miscellaneous material. The question as to how these exercises might be made to broaden the child's power of interpretation was presented. It was suggested that exercises based on different subjects and especially some adapted from study reading lessons might be valuable. Paragraphs with questions to be answered by yes or no and exercises calling for lists of persons, characters, action words, and descriptive words were described. The following were worked out and tried after the children had studied with the student-teacher the story of "Thorn Rose" in the Story Hour Reader, Book Three. They are 
typical of many exercises made by several different students from various types of reading material.

I. Read the paragraph written on the blackboard and answer the questions by yes or no.

"Deep shadows darkened the sunny rooms and the garden round about. A hedge of thorns began to grow around the palace. The hedge became thicker and higher as the days went by, until it was so tall that not even the palace towers could be seen."

a) Were the rooms darkened?

b) Was the garden sunny?

c) Could the palace towers be seen over the hedge?

2. "Everybody was fast asleep-the horses in their stables, the pigeons on the roof, the birds in their nests, the servants in the halls, the king and queen on their golden throne."

Make a list of all who were asleep.

3. "The horses began to neigh. The dogs began to bark. The pigeons cooed. The birds sang. The fire burst into flame."

Answer each question with one word.

a) What did the horses do?

b) What did the dogs do?

c) What did the pigeons do?

d) What did the birds do?

e) What did the fire do?

As the drill in this kind of work went on, attempts were made to increase the rate of reading of the slower readers. For quick recognition, time tests and time limits using lists of phonetic words were employed; words and phrases taken from reading lessons were drilled upon by means of flash cards; reading for thirty seconds and counting the number of words or lines read and other familiar tests for speed were given from time to time. In Measuring the Results of Teaching ${ }^{\mathrm{x}}$ by W. S. Monroe there are many suggestions in the chapters "Measurement of Ability in Reading" and "Correcting Defects in Reading"; suggestions may also be found in Reading in the Primary Grades ${ }^{2}$ by Frances Jenkins in the chapter "Problems in Form Mastery." In How to Teach Silent Reading to Beginners ${ }^{3}$ by Emma Watkins there are also many valuable suggestions. After reading material of this type the students made sets of flash cards containing phrases or sentences relating to

× Boston: Houghton Mifflin Co., rgr8. Pp. xviii+297.

2 Boston: Houghton Mifflin Co., I915. Pp. $x+124$.

3 Philadelphia: J. B. Lippincott Co., r922. Pp. I33. 
some one subject, as hygiene or civics. They were used in a little different way from the other flash-card exercises. For instance, a set of hygiene cards contained such sentences as the following: Brush the teeth three times a day; comb the hair; wash before eating. A card was flashed before the pupils for a second, and the child who could answer by saying, "We should brush the teeth three times a day," showed that he had read the card correctly. Several sets of cards relating to different subjects were made.

On March I3 Picture Supplement Scale 3 was again tried, the test being given this time by the supervising teacher to see what improvement had been made. In giving the test the children were directed to begin with the last exercise and work backward. Since in the test given in January the largest number of paragraphs read correctly was seven, it was not likely that the reading would overlap that done in the first attempt. The results showed a slight improvement, the average number of paragraphs read being 3.ro, while in January the average was 2.53 . The number reading none correctly was reduced from ten to three; two of the four who read seven in the first attempt advanced to eight and nine, respectively; one remained at seven; and one dropped back. In general, the groups moved forward a little. Figure I shows the distribution. It is quite probable that reversing the order of the paragraphs hampered some and affected the results somewhat.

In order to get at some of the individual difficulties the exercises were taken up one by one and the results discussed by the children and the teacher. It was discovered that some children stopped when they came to a word which was unfamiliar to them and kept their finger under it, evidently thinking that lack of knowledge of pronunciation and meaning of a single word meant that they could not successfully complete the exercise. For instance, the words "vicious" in paragraph I7, "represent" in I5, and "decorated" in II were found to have bothered a few in this way. This discovery led to the idea that it might help to give some exercises containing difficult and unfamiliar words which if skipped would not prevent the child from getting the meaning and completing the exercise. The purpose of reading is to get meaning, not to analyze words. Mastery of phonetic facts and analysis of words 
are essential to intelligent reading, but these things must be accomplished in lessons entirely apart from the reading lesson. It is important and sometimes difficult in the primary grades to offset the drill upon phonics and word analysis and center attention on getting meaning and sharing the writer's thoughts.

Many exercises, of which the following are examples, were worked out, using words entirely out of the child's vocabulary in order to train him to get the main thought of the whole passage even though it contained a word difficulty which he could not solve.

I. "Dick was a very refractory boy. Sometimes he disobeyed his mother. He often sulked and pouted when he could not have his own way."

Write three words which tell the naughty things Dick did.

2. "The robin is a migratory bird. Its head is black. Its wings and tail are brown. Its breast is rusty red."

Make a list of the colors found on the robin.

On April 24 Picture Supplement Scale 2 was given to determine any further improvement that might have resulted from the use of the remedial measures described. This time there was a marked improvement in the scores. The average number of paragraphs read was 5.8; the zero score entirely disappeared; and the score of twelve was reached by two of the class. The distribution of scores as shown by Figure I shows a much nearer approach to a normal situation.

On June 5, after four months of work along these lines, another test, Picture Supplement Scale 4, was given by the director of the school. Figure I shows the resulting distribution of scores. The distribution is still better in this last case, even though there is one zero and the two boys who previously made a score of twelve dropped back to ten and eleven. The average fell slightly, being 5.09, while for the previous time it was 5.8. In spite of these facts, however, the general result is more satisfactory as it shows a moving forward of the group as a whole.

While it is doubtless true that much drill has made the children more skilful in handling this type of test, it is also probable that as a result they will have a keener sense of appreciation and comprehension and will read more rapidly any material which they attack. 